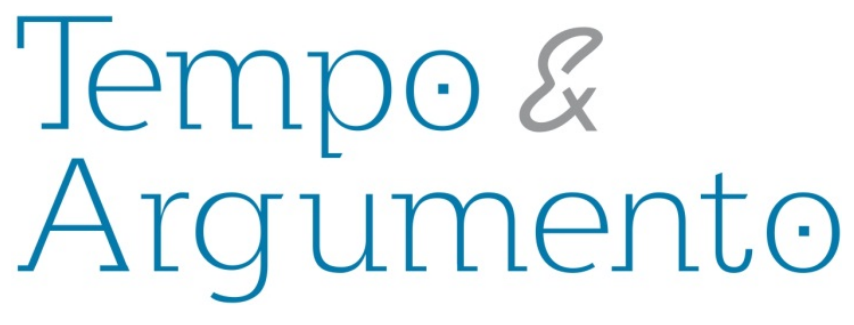

\title{
História pública e autorreflexividade: da prescrição ao processo
}

\section{Resumo}

A expansão e a internacionalização do movimento de história pública têm permitido visualizar com maior clareza os múltiplos entendimentos da expressão. Para além do modelo estadunidense, caracterizado pela ênfase na profissionalização do historiador, na ocupação de postos de trabalho fora da universidade e no reforço de uma identidade profissional desvinculada do ensino, outras visões têm emergido. Neste texto, proponho-me a discutir a capacidade de a história pública dinamizar a revisão e a revitalização dos princípios e das práticas do pesquisador. Para isso, discuto seu parentesco com a história oral com base em três experiências de investigação, anteriores ou em curso.

Palavras-chave: História pública. História oral.

Pesquisa Participativa.

\section{Ricardo Santhiago}

Doutor em História Social pela Universidade de São Paulo - USP. Estágio Pós-doutoral na Universidade Federal Fluminense - UFF. Professor do Instituto das Cidades da Universidade Federal de São Paulo - Unifesp. Professor do Programa de

Pós-Graduação em Estudos Culturais da Universidade de São Paulo - USP. São Paulo - SP - BRASIL rsanthiagoc@gmail.com

\section{Para citar este artigo:}

SANTHIAGO, Ricardo. História pública e autorreflexividade: da prescrição ao processo. Tempo e Argumento, Florianópolis, v. 10, n. 23, p. 286 -309, jan./mar. 2018. 


\title{
Public History and Self- Reflexity: From Prescription to Process
}

\begin{abstract}
The expansion and internationalization of the public history movement has allowed to visualize with greater clarity the manifold understandings of the expression. Beyond the US model, marked by an emphasis on the professionalization of the historian, the occupation of job places outside the universities, and the reinforcement of a professional identity unconnected to teaching, further views have emerged. In this text, I discuss the public history's potential to encourage the reassessment and reinvigoration of the researcher's principles and practices. To do so, I discuss public history's relationship to oral history building on three previous or ongoing research experiences.
\end{abstract}

Keywords: Public History. Oral History.

Participatory Research.

\section{História pública em expansão}

O movimento de história pública, não há dúvidas, está em franca expansão. Embora suas origens institucionais remontem a meados da década de 1970 particularmente nos Estados Unidos, onde uma associação nacional, um periódico especializado e diversos programas de pós-graduação se estabeleceram no período -, só nos últimos anos um esforço enfático em favor de sua difusão internacional tem se dado, evidenciando essa prática como uma das formas, entre outras, de refletir sobre as 

proliferação de eventos, publicações e oportunidades para a cooperação internacional ocasiões nas quais o Brasil ocupa um lugar de destaque - tem possibilitado visualizar, com bastante clareza, os distintos entendimentos sobre a história pública, uma expressão e uma prática que, longe de estar apaziguada, comporta conflitos e dissensos intelectuais e institucionais.

A imprecisão conceitual que paira sobre a história pública tem sido julgada com pesos distintos. Entre a indiferença dos que a consideram um arremedo pragmatista de debates sobre os usos do passado ou sobre a cultura histórica e a voracidade dos que aderem ao seu caráter aplicado como a derradeira oportunidade de redenção e justificação social da disciplina, a rubrica tem aberto possibilidades de interlocução estimulantes. Tem funcionado como um denominador comum para indivíduos que compartilham o impulso de publicizar conhecimento histórico, de adotar modelos participativos de construção de saber, ou de reconhecer a legitimidade discursiva de agentes que questionam de forma cada vez mais sonora e inventiva qualquer tipo de monopólio sobre o passado.

Esta, no entanto, é uma maneira generosa de encarar a história pública. Se por um lado ela constitui uma prática e um ramo de reflexões extremamente diversificado, também constitui - sobretudo em países anglo-saxões - um campo acadêmico bem estabelecido no qual estão em jogo postos de trabalho, oportunidades de publicação, posições em associações científicas e culturais, verbas de financiamento à pesquisa, marcadores de reputação e prestígio. Como causa e consequência desse fenômeno, disputas acirradas pelo controle da definição de história pública têm se dado, já que esse controle, naturalmente, repercute na própria posição que esses agentes tenderão a ocupar na estrutura de um campo cada vez mais internacionalizado.

Nesse cenário, a pedagogia da public history estadunidense - encarnada em programas de pós-graduação especializados e mais recentemente em manuais prospectivos, como veremos a seguir - tem se propagado sem dificuldades, instalando-se 
Noiret - membro fundador e presidente desta instituição entre 2012 e 2017 - apresentou um informe sobre a criação da sociedade italiana da área, da qual também foi seu principal articulador. Ele justificou a escolha do nome da organização - que não é “Associazione Italiana di Storia Pubblica”, mas “Associazione Italiana di Public History” alegando a busca por uma dissociação clara de outros entendimentos, em circulação na Itália e na Europa como um todo, em torno da expressão "história pública”. Segundo Noiret, tais entendimentos poderiam tangenciar debates sobre memórias públicas e usos do passado - e não seria propriamente com os intelectuais comprometidos com estes debates que a nova sociedade científica desejaria dialogar. ${ }^{1}$

A defesa institucional de um posicionamento como este soa, em um primeiro momento, um tanto quanto perturbadora, já que nessa perspectiva os fabulosos estudos italianos sobre memória pública de Alessandro Portelli e Luisa Passerini - para nos restringirmos apenas ao campo da história oral - seriam descartados. No entanto, essa colocação também é instrutiva. Permite depreender que a preocupação da sociedade italiana em filiar-se de maneira ostensiva à public history anglo-saxônica - ou, pelo menos, à sua triagem mais sonora - evidencia o entendimento de que a história pública não deveria se subsumir a reflexões e diagnósticos: almejaria, e deveria realizar, alguma forma de intervenção objetiva no espaço público, por meio da criação de produtos culturais e da ocupação de postos de trabalho, em conformidade com uma pedagogia específica previamente ritualizada.

Neste artigo, busco discutir algumas outras dessas posições. Revisito aspectos do processo de desenvolvimento e consolidação do mainstream da história pública estadunidense, buscando evidenciar como sua missão de reforçar o caráter profissional

\footnotetext{
${ }^{1}$ Para mais informações sobre a Associazione Italiana di Public History, ver: http://aiph.hypotheses.org. Uma das principais frentes de atuação da associação é o fortalecimento dos cursos de pós-graduação em história pública na Itália, que já são numerosos. Dentre eles, o Master in Public History da Università di Modena e Reggio Emilia e o Master di $1^{\circ}$ livello in Public History da Università degli Studi di Milano e da Fondazione Giancomo Feltrinelli.
} 
da atividade do historiador e de forjar uma identidade profissional desvinculada do ensino - missão primeiramente consubstanciada nos programas de pós-graduação criados na década de 1970 - vem ganhando novas formas (editoriais, inclusive) no contexto de expansão e internacionalização da história pública. Em seguida, discuto a frágil adesão ao modelo estadunidense no Brasil, sugerindo que aqui a rubrica tem sido (e pode ser) ativada principalmente para despertar um processo de autorreflexão por parte do pesquisador, capaz de dinamizar a revisão e a revitalização de seus princípios e práticas de pesquisa. Por fim, exercito essa reflexão examinando dois projetos de história oral por mim realizados, visando identificar suas contribuições para o fortalecimento de estratégias de construção participativa do saber.

\section{Identidade e formação: A pedagogia da história pública americana}

A história pública estadunidense surgiu em meados dos anos 1970, em um contexto de forte crise do mercado de trabalho universitário, impactado por um número decrescente de matrículas, cortes de pessoal e precarização das condições de trabalho (como o declínio do número de vagas com oferta de estabilidade profissional, o chamado tenure, aos docentes). A expansão de programas de pós-graduação nas universidades, muitos deles financiados por instituições como a Fundação Ford, levou a uma proliferação acelerada de doutorados, incompatível com a capacidade de absorção dos departamentos. Nesse período, a American Historical Association chegou a recomendar que os coordenadores de programas de pós-graduação em história enviassem aos candidatos aprovados, juntamente com as cartas de aprovação, uma outra carta: se a primeira os congratularia, esta os advertiria das mirradas perspectivas de emprego futuras.

Dentre os esforços coordenados por parte de organizações de historiadores ${ }^{2}$, perdurou aquele levado a cabo por Robert Kelley - historiador ambiental que atuava

\footnotetext{
${ }^{2}$ Em 1976, por exemplo, a American Historical Association (AHA) e a Organization of American Studies (OHA) juntaram-se em um esforço comum, fundando o Comitê de Coordenação Nacional pela Promoção da História, que visava reestimular o interesse público (especialmente de estudantes) na história, e a confiança nos historiadores.
} 
atividades profissionais, criando uma espécie de "carreira alternativa" para os historiadores. O movimento teve como seus principais marcos a criação da revista The Public Historian, em 1978, e do National Council for Public History, em 1979, estruturas que ajudaram a colocar em pauta a questão premente da empregabilidade do historiador (alertando para a capacidade de esse profissional ocupar postos de trabalho afinados às suas qualificações, mas tradicionalmente reservados a arquivistas e museólogos, por exemplo) e a forjar uma identidade profissional para os historiadores que não estavam em sala de aula (uniformizando a denominação, portanto, de um conjunto de atividades que Ihe precediam).

É verdade que outras instituições haviam desempenhado um papel importante no fomento a práticas públicas da história - como The American Association for State and Local History (AASLH) e The Society for History in The Federal Government. O NCPH, no entanto, buscou dar um passo adiante, definindo como parte integrante de sua missão a disposição de princípios voltados à preparação acadêmica para a atuação pública. ${ }^{3} \mathrm{O}$ corolário disso foi o surgimento dos programas de pós-graduação especializados, formulados para oferecer uma formação complementar e especializada voltada a preparar o historiador para atuar em outros espaços que não a sala de aula: empresas de comunicação, bibliotecas, museus e empresas de consultoria, por exemplo. ${ }^{4} \mathrm{E}$, embora cada programa possua suas especificidades - em geral informadas pelas necessidades e

\footnotetext{
${ }^{3}$ Na visão de Constance Schulz (1999), formação e identidade caminhariam lado a lado, caracterizando esse movimento: "o primeiro foi a criação de programas de história 'pública' ou 'aplicada' dentro de departamentos de história, conscientemente planejados para formar historiadores para 'carreiras alternativas' para além do professorado" (p. 29); o segundo, "a identificação crescente de historiadores formados que trabalhavam em agências governamentais e no setor privado com os laços comuns que tinham com a história, mais do que com as orientações profissionais específicas associadas aos seus empregos" (p. 29-30).

${ }^{4} \mathrm{O}$ primeiro desses programas - na University of California, Santa Barbara - foi fundado por Kelley. Em 1985, eram 50 programas em atividade nos Estados Unidos. Em 2008, mais de 110. Hoje, são cerca de 250 programas de estudo em história pública no mundo todo, 200 deles na América do Norte, e os demais predominantemente em outros países de língua inglesa. O NCPH mantém um guia regularmente atualizado no endereço: http://ncph.org/program-guide/. Para uma leitura sobre a missão e as características desses programas, ver: Zahavi, 2011.
} 
museus, sociedades históricas, arquivos e, sobretudo, no caso americano, de atividades ligadas aos parques nacionais, mas por meio do cumprimento de um certo número de créditos em uma instituição de ensino acreditada, à qual caberia transmitir um conjunto de conhecimentos previamente fixado. ${ }^{6}$

Nos últimos anos, essa mesma inspiração tem sido reforçada e renovada. Seja em artigos publicados em periódicos, em trabalhos monográficos ou em coletâneas, a produção intelectual estrangeira no campo da história pública produzida desde os anos 1970 poderia ser decomposta em três grandes frações: relatos de experiência; discussões conceituais, em muitos casos com caráter principalmente inspiracional; e textos reflexivos sobre os usos públicos do passado, a presença do passado na cultura, a percepção pública da história. Tem-se assistido, mais recentemente, à ascensão de dois outros gêneros que absorvem e empacotam a ambição pedagógica dos programas de história pública em publicações acessíveis.

O primeiro deles é formado pelos readers, handbooks ou companions, que consistem também em coletâneas de textos de diversos autores, mas assinalados por uma intencionalidade específica: a de reunir artigos - encomendados ou previamente publicados - considerados capazes de oferecer ao leitor uma introdução suficiente dos fundamentos de certa área, visando assim definir e estabilizar um cânone teórico. Podese citar, entre eles, The Public History Reader, organizado por Hilda Kean e Paul Martin (2013), e The Oxford Handbook of Public History, organizado por James B. Garner e Paula

\footnotetext{
${ }^{5}$ É isso o que recomenda o documento "Best Practices in Public History: Establishing and Developing a Public History Program" [Melhores práticas em história pública: Estabelecendo e desenvolvendo um programa de história pública], em diversos pontos. O documento foi preparado pelo comitê de currículo e formação do NCPH e adotado em 2016; em sua elaboração, foram consideradas as experiências de programas de pós-graduação encerrados em função da falta de apoio das comunidades e instituições locais. Ver: Weyeneth \& Vivian, 2016.

${ }^{6}$ Esta reflexão, apresentada aqui de maneira sintética, foi desenvolvida em maior profundidade na palestra "A quem pertence a história pública? Programas e manuais de ensino e a privatização de uma prática", no seminário "Comunidades de sentido: História e dimensões do público", realizado em 2017 na Universidade Federal Fluminense.
} 
History: A Practical Guide, de Faye Sayer (2015); Public History Textbook, de Thomas Cauvin (2016); e Introduction to Public History: Interpreting the Past, Engaging Audiences, de Cherstin Lyon, Elizabeth M. Nix e Rebecca K. Shrum (2017).

Não é meu objetivo resenhar esses livros, mas apenas apontar que eles têm seu valor: ajudam a questionar a falsa suposição, apontada por Rebecca Conard há pouco mais de dez anos, de que "a formação suficiente em história pública consiste apenas nos conteúdos e métodos usuais, de um lado, e em alguma experiência de trabalho no 'mundo real', de outro" (CONARD, 2006, p. 10). Sob outra ótica, eles confirmam o caráter eminentemente profissionalizante dos programas de estudo estadunidenses, segundo os quais a história pública é sempre prospectiva: consiste em um percurso de formação e desenvolvimento profissional no qual o historiador adquire e aperfeiçoa um conjunto de habilidades que o credencia a perseguir uma inserção específica, a depender das linhas de especialização e das oportunidades oferecidas pelo programa de pós-graduação escolhido.

Essas experiências, como já vimos, têm sido traduzidas em outros contextos intelectuais sob formatos variados: publicações, programas de pós-graduação, missões de cooperação. Seu entendimento como um modelo unívoco pode, no entanto, ser extremamente danoso do ponto de vista do cultivo de uma diversidade de práticas de história pública e da efetivação de intercâmbios intelectuais potentes.

\section{História pública e autorreflexividade}

No Brasil, o fabuloso legado intelectual e institucional da história pública estadunidense parece ter lugar não como um modelo a ser emulado, mas como um estímulo para a reflexão. Uma abordagem de tipo normativo e prescritivo da história

\footnotetext{
7 Embora tenham uma ambição comum, essas obras coletivas, em conjunto, revelam a presença de conflitos sensíveis no tocante à genealogia e à arquitetura teórica e conceitual da história pública. Ver, a esse respeito: Santhiago, 2014.
} 

introdução) em esforços de criação de um campo disciplinar e profissional separado. Em uma releitura peculiar, ela vem sendo ativada como um dispositivo conceitual capaz de ajudar o historiador a enfrentar os desafios contemporâneos de sua atividade. Não é, portanto, sugerida necessariamente dentro de uma chave prospectiva; para além da plasticidade da expressão e da sua capacidade de abrigar um número e uma variedade notável de práticas e reflexões, ela tem funcionado principalmente como uma espécie de categoria deflagradora de um exercício de retrospecção.

Sem constituir um exercício meramente reiterativo ou laudatório, a noção de história pública convida diferentes pesquisadores a revisitar suas investigações passadas ou suas práticas de trabalho correntes, ativando uma reflexão sobre o processo de construção do conhecimento que descortina a sua dimensão pública. Nessa leitura, não se pressupõe a história pública como um conjunto estável de técnicas a serem apreendidas e apenas consecutivamente emuladas, mas como uma prática reflexiva - um processo contínuo de aprendizado, baseado na reconstrução das práticas de trabalho a partir de experiências concretas - ou, se assim preferirmos, como um conceito capaz de dinamizar uma reflexão com consequências práticas.

É verdade que o estopim de uma articulação brasileira em torno da história pública foi um curso com perfil técnico, oferecido em 2011 na Universidade de São Paulo, e que em diferentes ocasiões - em minicursos, oficinas e palestras que vêm compondo a programação de eventos e em disciplinas eletivas de graduação e pós-graduação - essa rubrica tem sido convocada para denominar iniciativas de instrução ligadas a ferramentas ou habilidades práticas. No entanto, as soluções técnicas para a confecção dos inúmeros produtos culturais oriundos do ambiente acadêmico aos quais o público brasileiro tem sido apresentado - produtos extremamente diversificados, indo de exposições, livros e páginas na internet a jogos de tabuleiro, games digitais, aplicativos, videodocumentários, webseries e fanzines, entre outros - têm sido buscadas principalmente no trabalho coletivo e colaborativo, no interior de laboratórios, seja através do estabelecimento de 
alunos. Essa solução também explica, em parte, por que razão vários dos projetos de história pública desenvolvidos no Brasil rearticulam as dimensões alegadamente indissociáveis da pesquisa, da extensão e do ensino.

Além das experiências pioneiras desenvolvidas no Laboratório de História Oral e Imagem da Universidade Federal Fluminense, que se tornaram espécies de protótipos para a prática de história pública no Brasil, vale citar outros exemplos: o trabalho desenvolvido por Viviane Trindade Borges em torno dos patrimônios ligados a instituições de internamento em Santa Catarina, que envolveram estudantes de graduação (bolsistas de Iniciação Científica e alunos de diferentes disciplinas) da Universidade do Estado de Santa Catarina na preparação de exposições, vídeos e da construção de um memorial; o resultado da disciplina eletiva de história pública ministrada por Bruno Leal Pastor de Carvalho na Universidade Federal do Rio de Janeiro, um curta-metragem sobre a visita de Einstein ao Rio de Janeiro, que teve as tarefas de direção, edição, produção e roteiro distribuídas entre os alunos; ou ainda o projeto Desmistificando a ditadura, desenvolvido na disciplina de História do Brasil IV ministrada na Universidade Federal do Rio Grande do Sul por Caroline Silveira Bauer, na qual alunos de graduação produziram uma série de vídeos curtos, disponíveis em um canal no YouTube, planejados como um contraponto para visões de senso comum sobre a ditadura militar brasileira.

Em situações como estas, a história pública não necessariamente se apresenta como um destino, mas como uma solução, entre outras possíveis, que responde a um desejo de intervenção propositiva, crítica e qualificada, por parte de professores e estudantes, em decorrência de observações acerca das relações entretidas entre os públicos e seus passados. Nesse sentido, as práticas emergentes de história pública no Brasil desenham uma conciliação entre a tradição pragmática, aplicada e profissionalizante da public history estadunidense, orientada em função de resultados, e a reflexão teórica sobre o papel social da história e do historiador, inspirada como parte do 

resguardando suas especificidades - e confirma que ele ajuda a pensar.

\section{História oral: História pública a dois?}

É a partir de suas próprias práticas, temáticas e perspectivas que diferentes pesquisadores vêm mobilizando a noção de história pública, alguns observando os programas profissionalizantes estadunidenses para refletir sobre currículo e práticas de ensino; outros, os estudos de consumo da história ou de percepção pública sobre a história e a profissão do historiador para ponderar sobre a ampliação da circulação de produtos culturais ligados ao passado; e assim por diante. De minha parte, como praticante e estudioso da história oral, refleti sobre sua condição de história pública no mercado editorial e sobre a "história oral de inspiração pública" como uma das matrizes da história oral feita no Brasil (SANTHIAGO, 2011; 2013). Em ambos os casos, compreendi a história pública como uma possibilidade de conciliação entre a comunicação pessoal, íntima, que a entrevista de história oral possibilita, e a comunicação social, facultada pelas mídias que difundem conhecimento histórico para um público mais amplo. Em outras ocasiões, a história pública energizou o reconhecimento da polifonia de vozes na geração de interpretações sobre o passado propiciada pela história oral (SANTHIAGO; MAGALHÃES, 2017; SANTHIAGO, 2018).

A aproximação entre as duas práticas, no entanto, não se justifica apenas pelo entrecruzamento de interesses e projetos intelectuais individuais. Em seus escritos, a historiadora Marieta de Moraes Ferreira sugeriu que a história oral feita no Brasil contribuiu em muito para dinamizar a reflexão sobre a história do tempo presente. Em um texto instigante publicado na revista História, Antropologia y Fuentes Orales, Ferreira (2002) desenvolveu a imagem da história oral como uma "bússola" - como uma espécie de "laboratório epistemológico" no qual problemas que não são específicos das fontes orais, mas que permeiam a pesquisa histórica como um todo, são aguçados: a história 

as implicações da relação com o público na construção de um material que será utilizado como fonte; os múltiplos comprometimentos presentes nos atos interpretativos; a responsabilidade com a devolução da pesquisa e a publicização do conhecimento, e assim por diante. Nessa direção, Linda Shopes chegou a sugerir uma relação congênita entre ambas:

seria despropositado, ou seria um alargamento muito grande, sugerir que a história oral - um diálogo sobre o passado entre o historiador e um membro do público, ou, talvez dizendo melhor, entre duas pessoas com tipos diferentes de conhecimento histórico - pode ser considerada um protótipo para a história pública, uma "história pública a dois"? (SHOPES, 2016, p. 71)

A base para a reflexão de Shopes - ainda que apresentada obliquamente neste trecho - é o trabalho tão citado de Michael Frisch, A Shared Authority: Essays on the Craft and Meaning of Oral and Public History, de 1990. Nele, o autor advoga que a história oral é, por princípio, o produto de uma autoridade compartilhada; e sugere caminhos metodológicos para que o compartilhamento da autoridade aflua para um compartilhamento da autoria, frisando a raiz etimológica comum entre as palavras.

Embora a noção central explorada na obra, a "autoridade compartilhada", seja hoje um lugar-comum no discurso da história pública, seu lento processo de notabilização reforça o papel da história oral como uma prática incitadora da renovação da história pública - papel não consensualmente reconhecido. A esse respeito, aliás, um comentário do britânico Graham Smith em sua resenha à coletânea The Public History Reader, organizada por Hilda Kean e Paul Martin, é revelador. Segundo ele, a publicação provavelmente "provocaria alguma irritação entre os historiadores orais [oral historians] que consideram a história pública como parte importante de seus trabalhos". Para Smith (2013, p. 116), as menções à história oral na obra teriam sido poucas e insuficientemente desenvolvidas, a ponto de ele afirmar que "ao longo do volume parece haver uma tentativa de marginalizar a contribuição da história oral para a história pública". 
No tocante ao trabalho de Frisch, pode-se dizer que suas colocações foram primeiramente assimiladas pelos entusiastas dos depoimentos pessoais, já que, de certa forma, suas proposições colocavam-se na contracorrente do movimento mais amplo de profissionalização e de reforço da identidade profissional dos historiadores. O autor foi convocado ao diálogo por uma corrente de estudiosos em certa medida recessiva, que questionava ativamente o monopólio do historiador como intérprete do passado e que se engajava fortemente com as práticas da história comunitária, da história de família, e assim por diante: como já se afirmou, "a história oral (...) foi a primeira onda na série recente de desafios que golpeou a autoridade histórica tradicional” (ADAIR, FILENE \& KOLOSKI, 2011, p. 125). Porém, por meio do conceito que desenvolveu, Frisch de certa forma suspendeu a hostilidade entre essas duas posições. Ao sugerir um tipo de trabalho colaborativo no qual a expertise dos historiadores se encontraria com a experiência dos públicos, ele não minimizava o papel dos primeiros nem celebrava acriticamente a autoridade experiencial dos segundos.

O encaminhamento metodológico desse princípio, encarnado na remodelação do princípio da autoridade compartilhada para o aperfeiçoamento de processos de compartilhamento de autoridade ${ }^{8}$, ganhou nova forma, dentro da obra de Frisch, na proposta da "cozinha digital", onde fontes orais relativamente "cruas" seriam gerenciadas colaborativamente, "vendo o que é que podemos cozinhar, juntos, para qualquer pessoa que pudesse estar sentada esperando na sala de jantar" (FRISCH, 2016, p. 65). Se o universo digital - particularmente a Web 2.0 - forçou a revisão de práticas de pesquisa consolidadas em diversas disciplinas (o que se deu também nos estudos históricos, face à proliferação de fontes digitais de pesquisa, às possibilidades de difusão de conhecimento histórico oferecidas por diferentes suportes digitais, e também ao surgimento de comunidades digitais de aficionados e de iniciativas individuais que colocaram em cheque a primazia do historiador), FRISCH buscou radicalizar essa condição e refletir "sobre como os modos digitais podem superar a dicotomia entre criação de conhecimento e consumo de conhecimento" (FRISCH, 2016, p. 65).

\footnotetext{
${ }^{8}$ A esse respeito, ver na revista The Oral History Review o debate "Sharing Authority: Oral History and the Collaborative Process" (volume 30, número 1, 2003) e a série de resenhas que buscou reavaliar o livro de Frisch à luz de perspectivas contemporâneas (volume 44, número 2, 2017).
} 
A exemplo da "autoridade compartilhada", a "cozinha digital" consiste simultaneamente em um diagnóstico que identifica, agrupa e sintetiza oportunidades de colaboração preexistentes no universo digital (entendendo os recursos digitais como um incremento positivo em relação a situações de colaboração analógicas) e em uma inovação conceitual auspiciosa, capaz de motivar a proliferação e o aperfeiçoamento dessas práticas: segundo Frisch, a emergência de novos espaços digitais, colaborativos, minimizaria a distância entre histórias orais "cruas" e suas formas de apresentação públicas "cozidas”, permitindo que os narradores participassem do momento de geração de sentidos das entrevistas, em um processo de edição para apresentação pública. O que é de certa forma revelador tanto nos capítulos metodológicos do livro A Shared Authority (nos quais Frisch analisa, por exemplo, o processo de produção de um documentário, ou a obra editorial de Studs Terkel) quanto nos recentes desenvolvimentos em torno da cozinha digital (FRISCH, 2011, 2016) é que a própria necessidade de engendrar um novo vocabulário e um modo de pensar original aponta para o fato de que a história oral - não como posicionamento político, mas como dispositivo metodológico - não é inerentemente pública.

O pesquisador e teórico brasileiro José Carlos Sebe Bom Meihy foi um dos autores que contribuiu para desnaturalizar o caráter necessariamente público da história oral sugestivamente, ao afirmá-lo. Se por um lado ele postulou a história oral como um instrumento dotado de um "sentido de utilidade prática, pública e imediata" (MEIHY, 2005, p. 18), por outro ele desenvolveu toda uma construção teórica e metodológica necessária para dar consequência a esse axioma - e, ao fazer isso, demonstrou que a dimensão pública da história oral é um projeto (alcançável por meio de um conjunto específico de procedimentos), não um dado inescapável. Esse aspecto não pode ser negligenciado, sob pena de que se dê por certo que toda história oral pode ser caracterizada como história pública: a intimidade entre ambas não deveria ser um ponto de chegada, mas como, mais uma vez, a ignição de uma reflexão com consequências (metodológicas, se for o caso) práticas. 


\section{A dimensão pública da história oral, em três tempos}

As trilhas vacilantes de uma pesquisa recente que desenvolvi contribuíram para acentuar o caráter não-natural da colaboração em história oral e para evidenciar justamente porque incorri no erro de dar por certo sua dimensão pública e participativa que, na persecução de modelos interativos e dialógicos de produção do conhecimento, boas intenções não bastam. No caso desse projeto, havia de qualquer forma pelo menos duas boas razões para que eu tivesse em certa medida naturalizado a história oral enquanto história pública.

A primeira delas é que me fiei nos caminhos de uma pesquisa anterior na qual a história pública se realizou plenamente, tanto como construção participativa quanto como um projeto que gerou produtos culturais expressivos. Tratava-se de uma história oral de cantoras negras brasileiras cujos repertórios e trajetórias profissionais não se vinculavam ao samba ou a outros elementos supostamente característicos de uma afrobrasilidade. ${ }^{9}$ A partir de uma imersão na vida e no trabalho da cantora e compositora Alaíde Costa - meu plano inicial era o de biografá-la, o que veio a acontecer mais tarde, em outros moldes (SANTHIAGO, 2013) -, formulei uma questão de maior alcance: à glorificação de uma alegada "vocação" ou "aptidão" natural do artista negro para o samba correspondia uma espécie de interdição social, que limitava suas possibilidades de atuação profissional e suas chances de reconhecimento e consagração no campo artístico.

Minha abordagem da história oral foi decalcada dos modelos de Ecléa Bosi em Memória e sociedade: Lembranças de velhos (1979), e de Daphne Patai em Brazilian Women Speak: Contemporary Life Stories (1988), e colocada em prática no seio do Núcleo de Estudos em História Oral da Universidade de São Paulo (NEHO-USP), que valoriza a “função social e prática dessa experiência intelectual que teria uma dimensão pública importante" (MEIHY ;HOLANDA, 2013, p. 78). A abordagem deveria ir ao encontro do interesse de mulheres, negras, cantoras, de elaborarem narrativas sobre suas experiências pessoais e profissionais, passadas e presentes, à luz do problema que eu

\footnotetext{
${ }^{9} \mathrm{~A}$ investigação foi desenvolvida inicialmente como dissertação de mestrado, intitulada "Entre a harmonia e a dissonância: História oral de vida de cantoras negras brasileiras" e defendida em 2009 no Programa de Pós-Graduação em História Social da Universidade de São Paulo.
} 
imprevisto, vendo se constituir diante de si um espaço narrativo apto a acomodar temas usualmente interditados, ou pelo menos indesejáveis, em suas falas públicas usuais.

Embora realizado como uma investigação em nível de Mestrado, dentro de um programa de pós-graduação relativamente conservador, o projeto possuía uma vocação pública inescapável. Minha motivação primeira era, realmente, a de oferecer uma contribuição modesta a uma área de estudos acadêmica, a da história social da música feita no Brasil. No entanto, o trabalho adquiriu um papel importante para o próprio grupo de entrevistadas, irrompendo uma reflexão e um senso de pertencimento antes apenas latente. Ao contrário de boa parte dos grupos tradicionalmente focalizados pelos praticantes de história oral, minhas entrevistadas "tinham voz" - e suas vozes eram seus instrumentos de trabalho. Escutadas e celebradas quando do desempenho de seus ofícios, essas vozes raramente recebiam a mesma amplificação quando se prestavam a elaborar uma reflexão sobre as implicações de ser mulher, negra e não sambista no Brasil. Algumas das entrevistadas realizaram, no ato mesmo da entrevista, uma análise explícita desse fenômeno. Leila Maria, por exemplo, colocou:

Eu mesma não falo disso, porque tenho medo de que as pessoas não entendam o que estou dizendo e não apenas me tomem como preconceituosa, mas achem que estou usando isso como um recurso para justificar porque não acontecem mais coisas na minha carreira. Talvez enxerguem como um tipo de dor de cotovelo... Então, não dá. Não falo sobre isso com ninguém, porque as pessoas não assumem nem o preconceito geral - imagine, então, o especificamente aplicado dentro dessa área! (SANTHIAGO, 2009, p. 76-7)

Em função disso, a geração de produtos culturais a partir da pesquisa foi um anseio e uma demanda crucial apresentada pelas próprias participantes. Além da dissertação (com discussão historiográfica, metodológica e capítulos analíticos e interpretativos) e de artigos acadêmicos, o projeto gerou um livro patrocinado pela Secretaria Estadual de Cultura do Governo do Estado de São Paulo e distribuído em centenas de bibliotecas públicas; angariou ampla cobertura na imprensa, com dezenas de 
show de Alaíde Costa e Adyel Silva no Encontro Regional Sudeste de História Oral, em 2011). Mais importante: frequentemente, o trabalho que realizamos é invocado por essas artistas (em entrevistas e em suas páginas em redes sociais) como algo capaz de “autenticar" suas próprias colocações e de demonstrar o caráter social de percalços tão facilmente atribuídos a questões individuais ou a acidentes de percurso.

O êxito da dimensão pública do projeto - tanto como uma produção participativa quanto como matriz de uma variedade de produtos culturais eficazes - evidenciou a frutuosidade de uma aproximação, mesmo que inicial, de novos instrumentos metodológicos e técnicos: um processo de escuta que não se estendesse apenas à situação de entrevista, de um lado, e leis de incentivo, editais de cultura, direito autoral e modelos de licenciamento, de outro. Não obstante, esse mesmo êxito pode ter contribuído para animar a pressuposição de que um novo projeto de história oral equivaleria a uma iniciativa de história pública, a sugerir, em outras palavras, que o método narrativo que historiadores empregam para constituir fontes de pesquisa e outros profissionais e pesquisadores usam com as finalidades mais variadas se qualificaria, em consequência natural, como um método participativo.

É verdade que, entre esta investigação e a mais recente, participei de projetos coletivos de memória institucional e de diversos estudos em música e mídia que envolviam a história oral como um método de coleta de dados central. Escrevi ainda minha tese de doutorado sobre o desenvolvimento intelectual e institucional da história oral brasileira baseando-me principalmente em fontes escritas, bibliográficas, mas gravando também cerca de vinte entrevistas, em várias partes do país, que reorientaram as hipóteses iniciais e abriram possibilidades de aproveitamento imprevistas. Nenhum desses projetos foi entendido, nem mesmo a posteriori, como história pública. Portanto, o segundo elemento que pode ter contribuído para que eu desse por certa a dimensão pública do segundo projeto que irei comentar foi sua raiz: ele derivava de um projeto de história oral que mirava explicitamente a história pública. 
Foi no início da década de 1980 que a pesquisadora estadunidense Daphne Patai então estudiosa de literatura brasileira, distópica e comparada - deu início a um projeto pioneiro que resultou no livro Brazilian Women Speak: Contemporary Life Stories, publicado em 1988 nos Estados Unidos. Sustentada sobre longas histórias orais de vida registradas no Rio de Janeiro, em Recife e em João Pessoa, a obra tornou-se uma fonte de referência importante e original para leitores de língua inglesa conhecerem a realidade de mulheres no Brasil por meio de suas próprias vozes. Brazilian Women Speak tornou-se também um ponto de apoio teórico e metodológico importante para pesquisadores de história oral, como contribuição secundária. Patai tinha como preocupação primeira publicizar as histórias que ouviu, construindo uma história pública especificamente voltada à audiência americana. A visão distorcida da imagem pública da mulher, resultante do acesso privilegiado dos homens ao espaço público, a teria levado a "coletar, traduzir e editar histórias de vida de mulheres brasileiras contemporâneas, mulheres que geralmente não são ouvidas" (PATAI, 2010, p. 20), como escreveu a autora na introdução da obra. "Naquela época, não havia nenhum livro desse tipo em inglês. Agora já há vários - não muitos, mas vários. Meu objetivo sempre foi produzir um estudo que seria útil nos Estados Unidos, não necessariamente no Brasil”, relembrou Patai mais de duas décadas depois (PATAI, 2011, p. 174).

Cerca de trinta e cinco anos após o encontro da autora com suas dezenas de entrevistadas brasileiras, iniciei um projeto voltado a realizar novas entrevistas de história oral de vida com as mesmas mulheres gravadas entre 1981 e 1983. Das 60 entrevistas originais, encontramos o material referente a quase 50. Cerca de 20 mulheres foram entrevistadas por mim - das demais, muitas não foram encontradas, algumas faleceram e outras estão severamente doentes. Um pequeno grupo não ofereceu seu depoimento, sob várias alegações. Algumas eram prosaicas e diziam respeito à incompatibilidade de agenda ou à distância; outras, tocantes e profundas - mas todas sinalizavam para o desconforto dessas mulheres em mergulhar em um novo trabalho de memória, que implicaria adicionalmente confrontar uma representação de si oferecida há mais de três décadas. 
As entrevistas gravadas, em sua maioria, despertaram em mim o mesmo fascínio descrito por Patai. As leituras que ensejam são desafiadoras e têm exigido o compromisso de aprender mais sobre o envelhecimento, o desenvolvimento humano, as formas de pessoalidade, a relação entre tempo e lembrança, a neurofisiologia da memória, etc., em função dos vários caminhos de interpretação possíveis para dois dossiês de narrativas pessoais construídas com um intervalo de mais de 30 anos, em encontros intersubjetivos significativamente diferentes. No entanto, as relações estabelecidas em torno dos depoimentos foram caracterizadas por um tom algo protocolar: o entusiasmo das mulheres relatado por Patai não se reproduziu nos bastidores de nossos encontros, que parecem ter tido para elas pouco significado. O que realmente lhes interessou - e isso transparece tanto nas entrevistas antigas quanto nas recentes - não foi servir como respondentes em uma investigação acadêmica sobre a relação entre tempo, memória e narrativa, mas tomar parte em uma história pública que faria diferença no mundo, com base em um compromisso assentado, como Patai (2010, p. 23-4) escreveu em Brazilian Women Speak, no "reconhecimento, pela maior parte das mulheres que entrevistei, de uma espécie de vínculo com outras mulheres, as leitoras potenciais de suas histórias". Nas novas entrevistas, nosso trabalho de colaboração durou o tempo exato da gravação; e as entrevistadas tampouco demonstraram ansiedade em relação aos eventuais produtos dos nossos encontros. Essa história oral, afinal, tem algo de história pública?

No fim das contas, talvez: várias das entrevistadas pediram-me cópias das entrevistas que concederam nos anos 1980 e contaram-me, depois, que aqueles antigos relatos foram motes para reuniões de família e disparadoras de ocasiões de compartilhamento de histórias. Com isso, remeto ao estudo tão importante dirigido por Roy Rosenzweig e David Thelen, em meados dos anos 1990, nos Estados Unidos, que resultou no livro The Presence of the Past: Popular Uses of History in American Life (1998). No bojo de debates sobre a história pública, os autores - a partir de mais de 800 entrevistas - concluíram que, embora a maioria dos americanos demonstrasse desinteresse em relação à história como um saber especializado, estava profundamente envolvida em atividades ligadas ao passado, que iam desde assistir a filmes históricos até 
desafio em aberto, creio eu, consiste em persegui-la e explorá-la desde o desenho da pesquisa, seja a partir da recolha e da reelaboração de demandas explícitas ou da indução de modelos de pesquisa histórica participativa.

Nesse sentido - e retomando o meu argumento central, de que a história pública pode ser compreendida como um dispositivo capaz de animar uma reflexão com consequências práticas, estimulando a revisão e a revitalização dos princípios e das práticas do pesquisador -, o projeto que estou iniciando, intitulado "Arte e artistas na Zona Leste de São Paulo: Percursos de formação, desenvolvimento profissional e usos do espaço urbano", é orientado de saída pela busca deliberada desse aspecto, articulando os princípios da história pública ao projeto político-pedagógico da instituição que o abriga. Caracterizado por uma vocação extensionista, o Instituto das Cidades da Universidade Federal de São Paulo assume a extensão como um canal de mão dupla para o estabelecimento de uma interlocução entre a universidade e a sociedade, e não como um conjunto de atividades assistenciais ou como um locus para a disseminação pura e simples do conhecimento.

O projeto visa estudar as trajetórias de artistas oriundos da região, a fim de compreender - a partir da narração de suas experiências pessoais e profissionais - em que medida sua origem e inserção geográfica conformam seus vários campos de possibilidades. Adequa-se plenamente, portanto, aos procedimentos e às possibilidades abertas pela história oral - mas não se qualificaria, apenas por isso, como uma iniciativa de história pública. Passa a contemplar, então, um plano de ação que inclui a adoção de ferramentas colaborativas digitais para a identificação de possíveis entrevistados e o mapeamento de atividades de arte e cultura na região; que mescla diferentes estratégias para a coleta de dados, sendo a entrevista individual apenas uma delas; que articula atividades de pesquisa e de extensão comunitária em objetivos e ações comuns; que prevê o desenvolvimento e a divulgação de “produtos-em-processo", e assim por diante. 
A discussão dos aspectos procedimentais e formais envolvidos na produção de obras voltadas a públicos mais amplos - que necessariamente envolve a "tensão inerente entre o quanto a audiência deseja permanecer na história e o quanto de background é exigido para apresentar o período" (DUNAWAY, 2016, p. 167), por exemplo - é extremamente estimulante e valiosa, inclusive para a compreensão (e o desvirtuamento) das estratégias formulaicas implicadas em produtos editoriais, audiovisuais e digitais produzidos sem aproximação com a oficina do historiador. As discussões sobre divulgação científica e divulgação histórica, história e audiovisual, humanidades digitais e história digital têm pesado no aperfeiçoamento composicional e técnico na produção de bens como esses. Nesta última seara, exemplos inspiradores de publicização da pesquisa histórica em ambientes digitais foram oferecidos por Anita Lucchesi e Bruno Leal Pastor de Carvalho (2016), sendo que na enumeração de possibilidades feita pelos autores aparecem em destaque as ferramentas colaborativas. Por ironia, é justamente nesse âmbito que os debates sobre a história pública em ambiente analógico comportam - e necessitam - maiores avanços.

O desdobramento de um trabalho de história pública em produtos culturais palpáveis - em uma publicação ou, para retomar as formas que mencionei numa seção anterior, em um vídeo, uma série ou um memorial - é um caminho frutuoso para a realização da "devolução" da pesquisa, menos controverso do que propostas de compensação material direta ou de sessões de conscientização em comunidades, por exemplo. No entanto, não se pode garantir de antemão que projetos gerem produtos como consequência imediata; além disso, em muitas situações, o olhar restrito sobre o produto pode acarretar o descarte do processo em situações nas quais a dimensão processual da pesquisa seria precisamente aquilo que se alinharia às perspectivas da história pública. E, já que a história oral exemplifica esse fenômeno de maneira mais aguda, sua aliança com a história pública reforça o caráter desta não tanto como um produto mas sobretudo como um processo - ou como a integração entre ambos. Se for assim, concordaremos também que a história pública não se caracteriza fundamentalmente pela transmissão de um conjunto de habilidades técnicas capaz de viabilizar a construção de bens culturais - como propugna o mainstream da história 
pública estadunidense -, mas pela sua capacidade de promover uma transformação na relação das pessoas com o passado e também na relação do historiador com seu ofício.

\section{Referências}

ADAIR, Bill; FILENE, Benjamin; KOLOSKI, Laura (Orgs.). Letting go? sharing historical authority in auser-generated world. Philadelphia: The Pew Center for Arts \& Heritage, 2011.

ARENDES, Cord. Who we are: public historians as multiple personalities?. Public History Weekly, v. 3, n. 36, 2015.

CAUVIN, Thomas. Public history: a textbook of practice. New York: Routledge, 2016.

CONARD, Rebecca. Public history as reflective practice: an introduction. The Public Historian, v. 28, n. 1, p. 9-14, 2006.

DUNAWAY, David King. Rádio, história oral e história pública. In: MAUAD, Ana Maria; ALMEIDA, Juniele Rabêlo de; SANTHIAGO, Ricardo (Orgs.). História pública no Brasil: sentidos e itinerários. São Paulo: Letra e Voz, p. 165-72, 2016.

FERREIRA, Marieta de Moraes. Historia oral: una brújula para los desafios de la historia. Historia, Antropología y Fuentes Orales, n. 28, p. 141-52, 2002.

FRISCH, Michael. "From A Shared Authority to the Digital Kitchen, and Back". In: ADAIR, Bill; FILENE, Benjamin; KOLOSKI, Laura (org.) Letting Go? Sharing Historical Authority in a User-Generated World. Philadelphia, PA: The Pew Center for Arts \& Heritage, 2011. p. 12637.

FRISCH, Michael. 2016. "A história pública não é uma via de mão única, ou, De A Shared Authority à cozinha digital, e vice-versa". In: MAUAD, Ana Maria; ALMEIDA, Juniele Rabêlo de; SANTHIAGO, Ricardo. História pública no Brasil: Sentidos e itinerários. São Paulo: Letra e Voz, 2016. p. 57-69.

FRISCH, Michael; LAMBERT, David. "Between the Raw and the Cooked in Oral History: Notes from the Kitchen”. In: RITCHIE, Don (org.) The Oxford Handbook of Oral History. Oxford: Oxford University Press, 2011. p. 333-48. 
GARNER, James B.; HAMILTON, Paula (Orgs.). The oxford handbook of public history. Oxford: Oxford University Press, 2017.

KEAN, Hilda; MARTIN, Paul (Org.). The public history reader. London; New York: Routledge, 2013.

LI, Na. Public history in china: is it possible?. Public History Review, v. 21, p. 20-40, 2014.

LUCCHESI, Anita; CARVALHO, Bruno Leal Pastor de. História digital: reflexões, experiências e perspectivas. In: MAUAD, Ana Maria; ALMEIDA, Juniele Rabêlo de; SANTHIAGO, Ricardo (Orgs.) História pública no Brasil: sentidos e itinerários. São Paulo: Letra e Voz, 2016. p. 149-63.

LYON, Cherstin; NIX, Elizabeth M.; SHRUM, Rebecca K. Introduction to public history: interpreting the past, engaging audiences. 2017.

MEIHY, José Carlos Sebe Bom. Manual de história oral. 5. ed. São Paulo: Loyola, 2005.

MEIHY, José Carlos Sebe Bom; HOLANDA, Fabíola. História oral: como fazer, como pensar. 2. ed. São Paulo: Contexto, 2013.

PATAI, Daphne. Existe vida fora da história oral?. In: SANTHIAGO, Ricardo; MAGALHÃES, Valéria Barbosa de (Orgs.). Memória e diálogo: escutas da zona leste, visões sobre a história oral. São Paulo: Letra e Voz/Fapesp, p. 173-82, 2011.

PATAI, Daphne. História oral, feminismo e política. São Paulo: Letra e Voz, 2010.

ROSENZWEIG, Roy; THELEN, David. The presence of the past: popular uses of history in american life. New York: Columbia University Press, 1998.

SANTHIAGO, Ricardo. A história pública e suas vertentes em The Public History Reader. RESGATE - Revista Interdisciplinar de Cultura, v. 22, p. 103-106, 2014.

SANTHIAGO, Ricardo. Ele foi meu muro: Liberdade artística e liberdade narrativa em uma metaentrevista pública. Memória em Rede, v. 10, p. 83-111, 2018.

SANTHIAGO, Ricardo. História oral e história pública: Museus, livros e a cultura das bordas. In: SANTHIAGO, Ricardo; MAGALHÃES, Valéria Barbosa de (Orgs.) Depois da utopia: a história oral em seu tempo. São Paulo: Letra e Voz: Fapesp, 2013. p. 173-82

SANTHIAGO, Ricardo. Palavras no tempo e no espaço: agravação e o texto de história oral. In: ALMEIDA, Juniele Rabêlo de; ROVAI, Marta Gouveia de Oliveira (Orgs.). Introdução à história pública. São Paulo: Letra e Voz, 2011. p. 97-108. 
SANTHIAGO, Ricardo. Solistas dissonantes: História (oral) de cantoras negras. São Paulo: Letra e Voz, 2009.

SANTHIAGO, Ricardo; MAGALHÃES, Valéria Barbosa de. A zona leste de São Paulo e a história oral: história pública, políticas de memória e pesquisa acadêmica. Patrimônio e Memória, v. 13, p. 152-78, 2017.

SCHULZ, Constance. Becoming a public historian. In: GARDNER, James B.; LAPAGLIA, Peter S. (Orgs.) Public history: essays from the field. Huntington, NY: Krieger Pub Co, 1999. p. 23-40.

SAYER, Faye. Public history: a practical guide. London: Bloomsbury Academic Press, 2015.

SHOPES, Linda. A evolução do relacionamento entre história oral e história pública. In: MAUAD, Ana Maria; ALMEIDA, Juniele Rabêlo de; SANTHIAGO, Ricardo (Orgs.) História pública no Brasil: sentidos e itinerários. São Paulo: Letra e Voz, 2016. p. 71-84.

SMITH, Graham. The public history reader [book review]. Oral History, v. 41, n. 2, p. 115-7, 2013.

WEYENETH, Robert R.; VIVIAN, Daniel. J. Charting the course: challenges in public history education, guidance for developing strong public history programs. The Public Historian, v. 38, n. 3, p. 25-49, 2016.

ZAHAVI, Gerald. Ensinando história pública no século XXI. In: ALMEIDA, Juniele Rabêlo de; ROVAI, Marta Gouveia de Oliveira (Orgs.). Introdução à história pública. São Paulo: Letra e Voz, 2011 p. 53-63. 